\title{
PLURAL VALUES AND \\ ENVIRONMENTAL VALUATION
}

\author{
by \\ Wilfred Beckerman \\ and \\ Joanna Pasek
}

CSERGE Working Paper GEC 96-11 


\title{
PLURAL VALUES AND \\ ENVIRONMENTAL VALUATION
}

\author{
by
}

Wilfred Beckerman

and

Joanna Pasek

\section{Balliol College \\ Oxford \\ OX1 3BJ, UK}

\section{Acknowledgment}

The Centre for Social and Economic Research on the Global Environment (CSERGE) is a designated research centre of the Economic and Social Research Council (ESRC).

\section{ISSN 0967-8875}




\begin{abstract}
This paper summarises the conventional assumptions of welfare economics concerning the purely utility-maximising nature of consumer behaviour and the absence of any role for ethical considerations in judging the merits of market outcomes. It contrasts these assumptions with the experience of many contingent valuation $(\mathrm{CV})$ surveys, which appear to show that many people regard certain environmental values as incommensurate with ordinary market values. The plurality of values is alleged by critics of $\mathrm{CV}$ to justify both the incommensurability of environmental values with market values and the rejection of any moral obligation to allow the intensity of consumer preferences - as distinct from the reasons for these preferences - to guide environmental policy. The argument that environmental values possess some special intrinsic moral value is found to be unsubstantiated by any explicit moral theory or system. However, it is argued that the incommensurability of many environmental values can be justified in the context of a more flexible model of valuation that admits of incommensurability between certain kinds of valuations for various reasons independently of any reliance on a formal moral system.
\end{abstract}

The question of how society should make rational choices between incommensurate options is then discussed. It is argued that critics of $\mathrm{CV}$ fail to recognise the full implications of resource constraints and hence fail to address the problem of reconciling valid criticisms of $\mathrm{CV}$ with the need to recognise the resource constraints that have to be taken into account in any democratic method of environmental decision-making. 


\title{
1. Introduction.
}

\author{
High Heaven rejects the lore \\ Of nicely calculated less or more (Wordsworth)
}

A recent issue of Environmental Values (Volume 3, Number 4, 1994) was entirely devoted to criticisms, by a variety of contributors, of the technique of contingent valuation $(\mathrm{CV})$ frequently used in environmental decisions. For present purposes $\mathrm{CV}$ can be defined as a method of valuing the benefits of preserving or improving some asset (such as an environmental asset) on the basis of surveys in which people are asked how much they are prepared to pay to preserve, protect or restore the asset in question. ${ }^{1}$ Such valuations are a common feature of legal disputes over environmental damage and of cost-benefit analysis of environmentally-sensitive projects that have become increasingly mandatory in US and UK legislation concerning environmental policy.

We shall concentrate here on CV although there are, of course, other decisionmaking techniques in the area of environmental evaluation. But it is CV that has attracted most attention insofar as it epitomises the attempt to value the environment in monetary terms like ordinary marketable commodities. In any case, most of our comments here apply to any technique designed to measure environmental values in a manner that is commensurate with ordinary market values.

1 Sometimes, of course, respondents are asked variants on this question, such as how much they would require to compensate them for the loss of some environmental amenity. Monetary estimates of the value of environmental assets are not used only in CBA of new projects. They are also used in legal assessments of environmental damage that may have been incurred in the past. 
The criticisms of CV (and cost-benefit analysis, or CBA) have come mainly from environmentalists but also from a few philosophers. Some economists have also criticised CV - albeit not necessarily for the same reasons. ${ }^{2}$ But this paper is not concerned with economists' criticisms, even though these may well be the most powerful. It is concerned mainly with the criticisms that appeal to a model of human behaviour that expresses a plurality of values.

${ }^{2}$ See, notably, Diamond, and Hausman (1994), and Arrow et al. (1993). 


\section{Consumer Sovereignty, Maximising Behaviour and Plural Values}

One crucial ingredient of welfare economics, and hence of CV when used in CBA, is its acceptance of consumer sovereignty. This can be challenged on various grounds.

First, it is assumed that - with a few exceptions known as 'merit goods' - peoples' preferences are the correct guide to what is in their 'interests', or what adds to their 'welfare'. This positive assumption then underpins the value judgement that society ought to maximise the satisfaction of consumer preferences.

Secondly, it is assumed that agents (consumers or producers) have preferences that can be fully represented in single well-defined utility functions that agents attempt to maximise. This requires that the arguments in the individual's utility function are commensurate with each other in units - such as marginal utilities - that contribute to some single 'super-value' that could be maximised. Otherwise the notion of maxi-misation does not make sense. This positive assumption leads to the conclusion that the intensity of consumers' preferences for different goods and services is revealed by their relative expenditures on them. And, together with the previous assumptions, this implies that society's priorities should mirror the amounts that people are willing to spend on different goods.

Both the positive assumptions concerning individual behaviour and the value judgement that society's preferences ought to be some simple aggregation of existing consumer preferences have been subjected to powerful criticism, notably by economists such as Amartya Sen and others. Their criticisms have been directed mainly at the morally restrictive character of normative conclusions based 
solely on 'utility information' without much attention paid to the moral aspects of the underlying preferences. ${ }^{3}$

These well-known weaknesses in conventional welfare economics are reflected in two main lines of criticism of economic valuations of the environment in general and of $\mathrm{CV}$ in particular. First, it is argued that society has no more moral obligation to accept as given any particular existing set of preferences concerning the environment than it need accept its preferences in any other field in which moral values are involved. Secondly, most critics of CV - such as the contributors to the recent special issue of Environmental Values - maintain that the neoclassical model of the optimising, utility-maximising consumer is a travesty of the way that the consumer behaves in respect of environmental choices. This is alleged to be born out by the actual experience of CV surveys. It is argued that the single-end value model of consumer behaviour is no more applicable to environmental choices than it would be to choices involving, for example, issues of justice or integrity or freedom. The standard neo-classical model of the utilitymaximising consumer may well have proved productive in many fields and have greatly improved our understanding of an important area of human activity. But in areas such as the environment or other collective goods, the standard model of consumer behaviour may be misleading insofar as it cannot readily take on board the incommensurate plural values that influence peoples' preferences in such matters.

The plurality of end-values might seem so obvious to many people that there is hardly any need to labour the point. The same applies to the proposition that intrin-sic end-values are, by definition, incommensurate. Nevertheless, to take

3 Sen (1982) collects together some of his main contributions, but see also the chapters by Barry, Goodin, and others in Elster and Hylland (1986). 
these points for granted would mean ignoring (i) the extent to which commensurability between the values people place on the environment and ordinary market values is essential for $\mathrm{CV}$ to play the part it is expected to play in any CBA, and (ii) a long reductionist tradition in philosophy, of which utilitarianism is the most popular version.

To most philosophers a criticism of $\mathrm{CV}$ along the lines indicated would be merely the application to environmental valuation of a long tradition of theories of plural values, particularly those deployed by critics of utilitarianism. ${ }^{4}$ Indeed, some philo-sophers have specifically criticised, along anti-utilitarian lines, the misapplication of cost-benefit analysis to the resolution of conflicts involving environmental values. ${ }^{5}$

Advocates of plural values vary, of course, with respect to their particular choice of fundamental incommensurate values. But a common thread is the rejection of any unitary super-value governing peoples' choices, such as 'utility' in a utilitarian calculus or in neo-classical models of consumer behaviour. This rejection is based on the view that some values are simply incommensurate with the monetary valuations that characterise $\mathrm{CBA}$ and that are represented in $\mathrm{CV}$. This view is certainly supported by the evidence of responses to CV surveys, and by many other experiments concerning peoples' behaviour.

4 Some contributions that have a particular bearing on the subject of discussion here include Anderson (1993), Nagel (1979), Sen (1979, 1987), Raz (1986, 1991), Stocker (1990), Taylor (1991), Williams (1973, 1976). Sen points out that Adam Smith reproached philosophers for trying to reduce every value to some single virtue (Sen 1987, p. 24). It is not only economists who have been guilty of this error - if error it be.

5 For example, according to Bernard Williams, even if utilitarians (and CBA practitioners also) do not necessarily believe that every social value should eventually be amenable to treatment by something like cost-benefit analysis and that 'the common currency of happiness is money...they are committed to something which in practice has those implications: that there are no ultimately incommensurable values' (Williams 1976, p.105). 


\section{CV Responses and Environmental Valuations}

In normal markets in which private goods are traded the intensity of consumer preferences is measured (for a given income distribution) by the amount people spend on the goods in question. In the sphere of public goods, including most environmental assets, such an indicator of consumer preferences is not available. The usual problem with the environment, as with most public goods, is not that there are market imperfections but that there is no market. Consumer preferences may be sovereign, but there is no simple measure of them in such cases.

Various methods have to be used, therefore, to estimate how strong are peoples' preferences for protecting particular environmental assets. These include comparisons with similar marketed goods, where they exist. Some of these methods (e.g. travel time, or hedonic indices) are regarded as being unsatisfactory for various reasons, notably that they essentially measure only (and indirectly at that) the 'usevalue' that people derive from the assets in question. Since, by fairly common consent, this does not exhaust their value to individuals or society and account should also be taken of 'existence' or 'option' values, much use has been made of the CV method to which the criticisms set out in the Winter 1994 issue of Environmental Values were mainly addressed.

In this issue the main criticisms found in the well-known literature on the shortcomings of CV were set out and do not need repetition here. Criticism has also been voiced by economists. For example, Arrow and Solow voiced serious criticisms of $\mathrm{CV}$ as usually carried out, although they were optimistic that further refinements could overcome the main weaknesses (Arrow et al., 1993). Diamond and Hausman go much further than this and argue that there is little basis for such 
optimism and that '...CV is a deeply flawed methodology which does not estimate what its proponents claim to be estimating ...Thus, we conclude that current contingent valuation methods should not be used for damage assessment or for benefit cost analysis' (Diamond and Hausman, 1994, p.63).

One plausible explanation for the anomalies or disconcerting responses obtained in many $\mathrm{CV}$ surveys is that many respondents regard the questions put to them as asking them not so much how much they value the particular environmental asset involved but as asking a more general question concerning how much they are willing to subscribe to preserving the type of environmental asset involved - such as protecting wildlife or forests and so on. Alternatively, respondents' answers to such questions might indicate how much 'warm glow' they derive from support for environmental protection in general. ${ }^{6}$ This is reflected in the refusal of many respondents to attach monetary values to environmental assets at all. Indeed, they are often indignant at the suggestion that the environmental asset in question should be brought into relationship with the sordid measuring rod of money - to slightly modify Pigou's famous definition of economic welfare (Pigou, 1932, ch.1, $\sec .5)$.

Brian Barry, for example, reports that '...many respondents - up to a half in some surveys - become very angry when asked how much they would take in return for some degradation of the environment, saying that they are not in the business of accepting bribes. Quite a few are so indignant that they throw the interviewer out as soon as the question is asked' (Barry, 1995, p.156). Interviewees frequently react as if they are being asked improper - indeed outrageous - questions such as how much they would accept to perform some immoral act, with the result that

${ }^{6}$ Diamond and Hausman (1994, p.15), Sagoff (1994 pp.298-9), Kahneman and Knetsch (1992). 
they frequently respond either by refusing to put any figure at all on the in question or by putting an infinite value on it. ${ }^{7}$ Where they are given the opportunity they also frequently state that one should protect a clean environment 'regardless of the cost', that environ-mental goods have an infinite value, or that they should not be traded off against other important values.

In other words it does appear that responses to CV surveys indicate that people feel they are being asked, improperly, to put a price on something that cannot be valued in the same way that they value ordinary marketable goods. Their responses appear to reflect the fact that they are not merely concerned with their interests as private consumers but also with their interests as citizens in what is the 'right' policy for society to adopt. ${ }^{8}$

Insofar as this is true the weakness of $\mathrm{CV}$ is not a mere technical limitation that could, perhaps, be remedied by further refinements of the technique. It would be a more fundamental weakness. On account of the plurality of values or of modes of valuation, consumers' preferences for environmental assets are, in principle, unknowable in terms that are commensurate with ordinary marketable goods. An attempt to represent peoples' valuations of the environment in the same terms as their valuations of ordinary marketable goods would be a simple category mistake.

\footnotetext{
${ }^{7}$ Barry (1995), Sunstein (1995), Vadnjal and O'Connor (1994).

${ }^{8}$ Keat (1994, pp.334ff), Barry (1995 p.156).
} 


\section{Choice and Commensurability?}

There is no one universally agreed concept of incommensurability. For example, in the philosophy of sciences it refers to the alleged impossibility of comparing the merits of theories belonging to different scientific paradigms. In other contexts it may mean that options are not comparable in certain senses. But for purposes of their incorporation in a $\mathrm{CV}$ or a $\mathrm{CBA}$ what is required is that environmental values be commensurate with market values. This requires that the options are commensurate in what $\mathrm{O}^{\prime} \mathrm{Neill}$ refers to as 'strong commensurability', which is a very commonly used meaning of the term. ${ }^{9}$ For example, Sunstein's definition of incommensurability is that 'Incommensurability occurs when the relevant goods cannot be aligned along a single metric without doing violence to our considered judgements about how these goods are best characterized' (Sunstein, 1995, p.5). The Shorter Oxford English Dictionary defines 'commensurable' as "Having, or reducible to, a common measure; measurable by the same standard" It is this sense of commensurate, therefore, that we shall adopt here. ${ }^{10}$

Of course, it may be possible to compare some goods in terms of some single metric that is irrelevant to the way that they have to be characterised for the purposes of $\mathrm{CV}$. For example, it may be possible to compare two lakes in terms of the volume of water they contain without this having much bearing on the relative value that people will place on their environmental value.

\footnotetext{
${ }^{9}$ O'Neill (1993, p.103). See also Griffin (1988), Stocker (1995), and Sunstein (1995).

10 The definitions followed here differ somewhat, therefore, from the very well-known definition of incommensurability proposed by Joseph Raz, namely that 'A and B are incommensurate if it is neither true that one is better than the other nor true that they are of equal value' (Raz 1986, p.322).
} 
There are three questions. First, does the mere fact that people do succeed in making choices in all sorts of situations in which they may appear to be faced with incommensurate options mean that all options must be commensurate after all? Secondly, if not and if genuine strict incommensurability can be accepted in some cases, what reasons, if any, can be given for believing that some (but not necessarily all) environmental values are incommensurate with ordinary market values? Thirdly, insofar as people make choices between incommensurate options in what sense can their choices be regarded as rational?

As regards the first question, the answer seems to be 'no', except, perhaps, to most utilitarians. Even limiting ourselves to prudential values, the choices that people make in the course of their lives frequently involve incommensurate options of one kind or another. The fact that various components of 'well-being' can, at best, each be ranked according to different scales, does not mean that they can be made commensurate with each other by being converted into some 'super-value' (Griffin, 1988, pp.75-90). 'The values a person holds are not unified in anything other the being his values' (Griffin, 1988, p.32).

People often also make choices between options that comprise non-prudential values of the kind often included in a list of intrinsic final ends, or plural values such as loyalty to one's friends or family, integrity, concern for justice, and so on 11. And only die-hard utilitarians and Chicago economists would suggest that intrinsic moral values are commensurate. Comparisons can be, and often are, made between goods that differ in terms of intrinsic values without it being

11 See, for example, Bernard Williams's example of George's problem of whether to take a job in a laboratory engaged in chemical or biological warfare in order to provide for his family - where choice cannot be based on some 'super scale' of prudential values. Williams (1973, p.98). 
possible for them to be valued in terms of some common numeraire. ${ }^{12}$ In fact we often do not need units at all - and so do not need common units - to make comparisons between options. ${ }^{13}$ The frequency of incommensurate values in the choices made in daily life does not necessarily imply that, after all, some single end-value is behind all our decision-making, and that '... the ranking is a kind of technique for measuring this single value' (Raz, 1986, p.327). It does not validate the conventional economics assumption that 'revealed preferences' in the act of choosing must indicate some unique super value that is being maximised.

${ }^{12}$ Sunstein (1995, p.6), Stocker (1990, pp.168-177, 1995, p.9).

13 Stocker (1990, pp.168-177). Aldred's suggestion (1994, p.395) that the act of choice shows that agents have an ex-post, but not an ex ante, utility function the domain of which included the options in question is not, however, very convincing. 


\section{What is 'Incommensurable' About Environmental Values?}

\subsection{Do environmental values have some special moral status?}

The next question is whether environmental values - or rather the services that people derive from the environment - enjoy some special moral status like common intrinsic values, such as justice or integrity or freedom. For example, the environmental philosopher, Bryan Norton, represents the views of many of his colleagues when he writes that 'Environmentalists are moralists, and one of the ways they show this is by taking an active concern for both the options for experiences and the values of future people' (Norton, 1994, p.323).

Insofar as environmental values had the special moral status claimed for them there would be two implications in the present context. The first is that the environment is an example of the welfare economics' failure adequately to allow for ethical judge-ments on the value of the ends, or satisfactions, that people pursue. $^{14}$ It is argued that, unlike market valuations which are guided by 'wantregarding' principles, environmental decisions should, be guided by 'idealregarding principles'. ${ }^{15}$ These do not take existing preferences as given. Instead, they would call for procedures that provided suitable opportunities for preferences in accordance with views as to the moral status of the various options open to policy makers.

The second implication of the alleged special moral status of environmental services would be that they would be incommensurate with ordinary market

\footnotetext{
${ }^{14}$ See, in particular, various writing by Sen whose 1987 book includes, perhaps, the best summary up to that date of some of his main observations on this issue. (See also Phelps, 1975).

${ }^{15}$ See Barry (1995, esp. pp.147-159), and O'Neill (1993, pp.61-64).
} 
values. Few people - even including economists - would claim that intrinsic moral values can be made commensurate with each other, or with market values which are essentially prudential values. ${ }^{16}$

The key issue, therefore, is how valid is the claim by most environmentalists to the effect that environmental preservation constitutes one such intrinsic moral value. After all, it can be claimed that the environment simply provides use-values like any other 'commodity' and the fact that these may be different from those derived from other commodities does not justify their being singled out for special moral status. The environment provides food and sustenance, aesthetic satisfactions, and may fill us with awe and wonder at its vastness and diversity. But so do many other things, many of which are marketed like ordinary commodities. And others, like medical or educational or other services, which might have to be partly sacrificed in order to spend more on environmental preservation, appear to correspond even more directly to intrinsic moral values, such as respect for peoples' lives and for the need to provide people with scope for development of their faculties? It is difficult to see in what way the environment is in some moral class of its own?

The view that environmental values have some special moral status does not seem to be grounded in any clearly defined moral system that differentiates them from many other competing values, economic and non-economic. Hence, if the validity of the claim that some particular value possesses initrinsic moral value depends on it being explicitly grounded in some substantive moral theory (Griffin, 1988, pp.77-78), the 'moralist' critics of CV would be on weak ground. They rarely attempt to base their claims on any fully articulated moral system. It is usually

16 The term 'prudential' here is used in the customary philosophers' broad sense. That is to say, it does not indicate merely a cautious concern with one's future but encompasses everything that affects one's self interest. (See Griffin 1988, p.4). 
thought to be sufficient to appeal to what might be a quite arbitrary moral choice or preference.

Even if such a moral theory could be maintained, there would still be some question as to how far moral values must always 'trump' prudential values, and how far allegedly 'moral' environmental values 'trump' other intrinsic values (Griffin, 1988). Inadequate attention to the need for a clear moral theory is the counterpart of the inadequate attention paid by most environmentalist critics of $\mathrm{CV}$ to the ethical value of alternative use of resources - e.g. on health, education, housing, and even simple privately appropriated 'utility'. If, as suggested above, there is no clear case for attaching special priority to environmental values on moral grounds, there is even less justification for ignoring the need to make tradeoffs between environmental values and other claims on resources. The problem of choice is unavoidable.

\section{2 'Incommensurability' and 'higher modes of valuation'}

However, for purposes of treating environmental values as incommensurate with ordinary market values, rather than treating them as 'trumping' other values, a distinction between environmental values and other values in terms of some substantive moral system might be imposing an unnecessarily strict requirement. To most people the possession of some special intrinsic value would satisfy a sufficient condition for incommensurability, but it is not a necessary condition for incommens-urability. For this more modest purposes the issue would be whether there are qualitatively different modes of valuation some of which are incommensurate with others and that reflect a 'higher mode of valuation' that cannot be made commensurate with ordinary costs and benefits. Such a position 
could be more easily defended in terms of 'ethical considerations' that arise in environmental choices, but that do not require that some special intrinsic moral value is conferred on the environment in the context of a coherent moral system. ${ }^{17}$ (In fact it might be less contentious if the term 'plural values', which is associated with moral theory, were to be replaced by some morally more neutral term, such as 'multiple values' or 'diverse values').

One relevant 'ethical consideration' might be the desire to leave open to other people, including even future generations, the possibility of deriving use values from environmental assets. This view is the basis of the 'option values' or 'existence values' that many people attach to the environment, as distinct from its use value. The ethical consideration lies in the sense of obligation to others, or the sense of fairness to future generations. Similarly, contemporary norms of consideration for non-human species could also qualify as an ethical consideration that imposes some constraint on our pursuit of purely self-regarding ends. Insofar as environmental values partly reflect such ethical considerations it is difficult to defend the view that they are substitutes for ordinary commodities and hence can be correctly valued in $\mathrm{CV}$.

What is being argued here then is simply that some environmental goods should be subject to 'higher' modes of valuation than those that are appropriate for the ordinary marketed goods that are privately appropriated for 'use' by the purchaser. Elizabeth Anderson's recent contribution to the theory of values in ethics and economics deserves special mention here (Anderson, 1993). This is not because her theory represents a radical departure from other theories of valuation, or various theories of 'expressive rationality'. Indeed, it overlaps with them in many

17 We follow here the distinction made between systems of morality, on the one hand, and ethical considerations, on the other, as set out by Bernard Williams (1993, pp. 6-7). 
respects. ${ }^{18}$ Anderson's theory, like Etzioni's and others', also owes much to sociological and psychological theories of the way that people play roles in society that are influenced by their view of how other people in society will expect them to behave, or of the way that norms in society are determined. But Anderson pays special attention to the implications of her version of expressive rationality for the role of cost-benefit analysis in environmental evaluation and other public issues.

Most theories of plural values refer to values such as liberty, justice, friendship, knowledge, or pleasure. ${ }^{19}$ But Anderson's pluralism extends also to evaluative attitudes, such as love, admiration, and appreciation, by which one adjusts one's attitudes to different goods. Our valuations of 'objects' (goods, people, animals, etc.) are thus often affected by our relationships to the goods or people concerned. Simple examples of this given by Anderson are the way in which we may value an ugly useless gift from a friend on account of our relationship to the friend, or the way in which parents' adoration of certain features of their children that they would not expect other people to find adorable, express their love for the children. What people regard as an appropriate valuation will depend partly on the ideals of the valuer and her social relationship to the object of her valuation (Anderson, 1993, pp.24-25).

In the Anderson expressive valuation theory it suffices for people to regard goods as incommensurate '...if they are not candidates for the same mode of valuation' (Anderson, 1993, p.70). Something may be valued higher than something else if it makes 'deeper, qualitatively more significant demands on the attitudes, deliberations, and actions of the valuer' (Anderson, 1993). This resembles Charles

18 See, for example, Amitai Etzioni (1988). Unlike Etzioni, however, Anderson does not try to base her distinction between different kinds of value on the extent to which they constitute 'moral' values.

19 See, for example, Nagel (1979, pp.129-131), and Taylor (1991). 
Taylor's view that there '... are languages of qualitative contrast which we are quite ready to recognise as non-moral, even bearing in mind the fuzzy boundaries of the domain which this word picks out' (Taylor, 1991, p.136).

Suppose, for example, that the famous Canova sculpture, 'the three Graces' was attacked and smashed beyond repair by some tourist, who then cheerfully offered to pay $£ 8$ million, a sum greater than its latest market price. If one then accepted that this left the country no worse off one would be treating the sculpture as substitutable with any other objects that could be bought for the $£ 8$ million in question. In that case one would have been equally ready to do a deal with any vandal who offered to pay $£ 8$ million for the pleasure of smashing up the Canova.

Most people, however, would feel some sense of loss irrespective of the price that the tourist offered to pay in compensation. It would be thought that $£ 8$ million worth of, say, automobiles or other goods that could be bought with the money could not replace the Canova. This was a unique work of aesthetic beauty that arouses admiration and respect and hence a type of valuation that is incommensurate with the mere purchasing power of the price that somebody had been prepared to pay for it. Such an attitude to the Canova might not, however, rule out selling it to some overseas museum. For one would expect that it would be treated with the same respect and admiration as at home. It would not be the same as cheerfully letting some vandal smash it up for $£ 8$ million. On the other hand, keeping the Canova in Britain may have some symbolic significance, symbolising the attachment of the nation or community to respect for works of art that aroused different kinds of satisfactions than those provided by ordinary marketed goods and services.

When personal relationships are involved, people are even more inclined to believe that many objects or actions cannot be valued in monetary terms because 
this would express a view of some relationship that would conflict with their conception of what the relationship really involves. An extreme, but nevertheless relevant, example of this is given by Raz in a comparison between two situations (Raz, 1986, p.349). In one situation a person is offered a certain sum of money on condition that he leaves his wife for a certain amount of time. In the other situation the same person is offered a job somewhere that will take him away from his wife for a similar length of time but for which he will be amply paid. Most people would agree that it would be perfectly legitimate - subject to his wife's consent - for him to accept the latter proposition but totally inappropriate for him to accept the former. For in the former case he is simply treating his wife like a commodity and is willing to dispense with her for a period of time if suitably compensated. Such a behaviour would be rightly regarded by the wife as contemptible. In the latter case, however, although the wife would still be deprived of her husband's company for the same period this would not be the intended object of the transaction, even if it is a predictable consequence.

Another similar example of the role of personal relationships in our valuations is Sunstein's example of a situation in which one found that one had to cancel a longstanding engagement to have lunch with an old friend for some reason or other (Sunstein, 1995, p.3). Suppose then that one offered the friend some monetary compensation for his disappointment. Most of people would be shocked at such a proposal. Why? Because they do not think that a monetary valuation is appropriate in these circumstances.

These examples illustrate our basic intuition that some 'objects' or actions should be valued in ways that are not appropriately valued in monetary terms as if they were simply substitutable with any goods that could be purchased with money. And it is easy to see that the environment is one such object insofar as it appeals to 
'higher' modes of valuation, some aesthetic, some appreciation, and some of a character that reflect relationships with, or ethical considerations such as a sense of obligation to, other people and generation. 


\section{Market Valuations and Collective Environmental Assets}

At the same time many of the above considerations - personal relationships, social norms, and so on - also influence the way we value the ordinary marketable goods that we purchase. Nevertheless, although we can reflect our expressive valuations in ordinary private market transactions we cannot usually do so adequately in cases involving public assets. This applies to environmental assets, which may have non-use value and to which we may have special relationships on account of our commitment to other people, including, perhaps, future generations.

Firstly, CV interprets the monetary value put on environmental assets as indicating simple substitutability with any other bundle of marketed goods, the contribution of which to society can be measured simply by the intensity of preferences expressed through willingness to pay. But some features of the environment, like the Canova in the above example, may not be simply substitutable with ordinary marketable goods or services.

Secondly, all that matters in ordinary market purchases is the intensity of our desire to acquire, or use, the object in question, not our reasons for doing so. In buying a $\mathrm{CD}$ we do not need to justify our preference for Mozart over pop. All that matters is whether we can pay. In the market we can only register our valuations by 'exit' rather than by 'voice' (i.e. either buying or not buying, rather than by presenting arguments for or against public support for some particular asset).

This may not matter for privately appropriated goods. We may feel that some peoples' preferences for certain goods or activities are strange, distasteful or even contemptible. But as long as they merely affect their own patterns of expenditure 
we may not feel any need to go out on the streets and persuade them to 'culture-up'. We may not care much if rich people spend their higher incomes on one particular privately appropriated good rather than another. But we may object to the degree of our - and everybody else's - enjoyment of the environment being determined largely by the preferences of those members of society who happen to be the wealthiest. With private goods, the consequences of one's choice fall on oneself. With public goods one is affected by the consequences of other peoples' choices, which, if they are reflected in $\mathrm{CV}$, will also depend partly on who has the highest incomes. $^{20}$

Finally, the personal relationship between buyer and seller is usually irrelevant to most ordinary market transactions (with the exception of markets such as the labour market). Both buyer and seller are primarily - if not always exclusively concerned solely with their own interests in the transaction and not with any other aspect of their relationship. We go to a shop, we buy something, we walk out. In most cases buyer and seller do not expect to meet again, and even if they do they will still assume that each other's behaviour is essentially egoistic, however 'highly' valued may be the objects involved. By contrast, the valuation one places on public environmental assets is influenced by relationships - of obligation, or duty, or fairness - to other people, including possibly future generations. It may also express the satisfactions that one obtains from shared experiences. ${ }^{21}$

At the same time, although some environmental values may be incommensurate with ordinary commodities so that trade-offs will be complicated, none of the

20 This point is well developed in Jacobs (1995).

21 Anderson also argues that the fact that marketed goods are valued by purchasers as appropriate objects of use restricts the mode of valuation that is appropriate to them, since 'use' subordinates the objects to one's own ends, which she contrasts with higher modes of valuation such as respect and recognition of intrinsic values (e.g. 1993, p.144). 
above implies that they 'trump' use-values or that there are, for example no circumstances in which the Canova should be sacrificed. The next question, therefore, is whether there is any rational method of making the necessary choices and trade-offs. 


\section{Incommensurability and 'Rational Choice'?}

It has been argued above that some environmental values can be accepted as incommensurate with ordinary market values without their being grounded in any coherent moral system. It has also been argued that incommensurability in general is not an insuperable bar to choice. ${ }^{22}$ This is hardly surprising given that where options are not even comparable - let alone commensurate - people do not remain in a state of permanent indecision, like Buridam's ass. Nor do they usually just toss a coin. ${ }^{23}$ But in what sense can whatever procedure they follow be described as rational? And does the answer to this question indicate how society should make rational choices between possibly incommensurate environmental values and other valued uses of resources?

In neo-classical economics rational choice implies commensurability because 'rationality' is interpreted in the narrow sense of instrumental rationality - i.e. the selection of means to maximise some clearly defined single end-value. ${ }^{24}$ But the ubiquity of choice between incommensurates shows that one must drop the assumption that instrumental rationality governs all aspects of individual decision making. Instead, if choice is still to qualify as rational, rationality has to be interpreted more widely to mean more than merely satisfying the usual criteria of

${ }^{22}$ See also Stocker (1990, pp.166-7).

23 Of course, it may well be that the choices they make in these circumstances are mistaken, though it is not obvious, in such a situation, in what sense a choice could be the wrong one. (Raz 1991, p.86)

24 This point has been very forcibly made by Sen (1987, p.15) and Bernard Williams (1993, p.17). See an excellent survey of concepts of rationality in economics by Hargreaves Heap et al. (1992). 
consistency and transitivity, which are well-known to be, at best, necessary but not sufficient criteria of rationality. ${ }^{25}$

A wider concept of rational choice would merely require that rational appraisal plays a key role in the valuation of the options and in providing a justification for any of them. This could comprise having good reasons, rather than mere unreflective whim, for valuing the incommensurate ends that the different options will promote - e.g. one action will promote justice, another will take account of one's loyalty to a friend. According to Raz 'Rational action is action for (what the agent takes to be) an undefeated reason. It is not necessarily action for a reason which defeats all others'. ${ }^{26}$ In other words, peoples' choice of ends should accord with standards of value that are not arbitrary and that reflect how they think that objects are appropriately valued, what social norms affect their valuation of the goods in question, and how far they think that their valuations are consistent with their conceptions of the kind of person they ought to be. The interpretation of rational choice here thus matches theories of 'expressive rationality' and psychological theories of 'procedural rationality'. ${ }^{27}$ Such a wider concept of rationality does not even require compara-bility, let alone commensurability.

The conclusions at this stage, therefore, are (i) some environmental values may be regarded as incommensurate with market values without having to appeal to exaggerated claims of moral superiority; (ii) this precludes their being brought into

25 They could easily allow that many mad people behave rationally, as might people who behave in a consistent manner without using their reason at all as a guide to their behaviour, or even be conscious. See, for example, Sen 1977 ('Rational Fools') pp.322-3 and Sen (1987, pp.12ff), Etzioni (1988, pp.136-143).

${ }^{26} \operatorname{Raz}(1986$, p.339). Much the same point is made by Sen (1987, pp.67-68).

27 For example, Simon's definition of procedural rationality is that 'Behaviour is procedur-ally rational when it is the outcome of appropriate deliberation' (Simon, 1979). 
relation with the measuring rod of money, but (iii) it does not preclude, at the level of the individual, that choices can be made between environmental and other incommensurate values in a rational manner. 


\section{8. 'Rational' Choice for Society Under Incommensurability}

However, it may be argued that rational choice between incommensurate options may be perfectly feasible for individuals but much more difficult for society as a whole when a choice has to be made between alternative allocations of limited resources. An individual may not need a simple paradigmatic basis for choice between incommensurates. After careful reflection it may well be that she can make choices in the light of her ideals and personal conceptions of the sort of person she wants to be rather than with the aid of some clear-cut utilitymaximising decision rule. At least she will be in touch with her own tastes and temperaments and so on, as well as be aware of the strength of the intrinsic values to her of the various options facing her.

But these conditions will not usually be satisfied to the same extent in society at large. To reach decisions that have widespread social consequences and that will inevitably mean that there are some 'losers', society may have a much greater need for what appears to be an objective and impartial formula for trading off one option against another. Merely having 'undefeated reasons' for valuing the available options may not be enough. Society may need some precise 'algorithm' for reaching decisions that is widely accepted by the population as a whole as being 'fair' and 'sensible', which may mean that they are based on precise formulae and do not leave much scope for individual interpretation by, for example, officials or politicians or local pressure groups.

Furthermore, the extent to which the appropriate valuation by individuals applies to social choice raises problems similar to those raised in moral theory by 'agentrelative values'. ${ }^{28}$ It may not be legitimate to pass readily from agent-relative

\footnotetext{
${ }^{28}$ See, for example, Nagel (1980, p.119), Parfit (1981).
} 
valuations to social valuations. For example, it may be right for an individual to take the view that a member of his family or a close friend cannot be valued in monetary terms. This may be because the relationship to the valuer is of a deeper and more significant kind - of love, loyalty and so on - than is the valuer's relationship to, say, his car (except in Italy) or to his (dog, except in England, perhaps) or to his firm (except in Japan). In that case it may be perfectly normal for the valuer to make some enormous financial sacrifice to protect the loved one from danger or to provide required medical attention.

But one cannot expect such agent-relative values to be respected by society as a whole. For example, even if every member of society was prepared to make enormous financial sacrifices in an attempt to save the life of their loved ones nobody would argue that society should devote the whole of GNP - if that is what would be required - to reduce the risk of saving one more unidentifiable 'statistical life' (See Anderson, 1988, pp.67-69). Social valuations do not have to be - and indeed often could not possibly be - simply the aggregation of individual agentrelative valuations.

For one reason or another, therefore, society may need some acceptable rational algorithm for ranking alternative allocations of resources. And if $\mathrm{CV}$ is rejected in such cases what is the alternative? Is the choice between '...a unified but artificial system like cost-benefit analysis, which will grind out decisions on any problem presented to it' and '..romantic defeatism, which abandons rational theory because it inevitably leaves many problems unsolved' (Nagel, 1979, pp.121-137). According to most critics of $\mathrm{CV}$ this is not the choice. They propose an alternative, namely public debate and discussion of the merits of the environmental projects in question. 
For example, in judging the relative merits of rival scientific theories - e.g. Darwinism against creationism - one would evaluate them in terms of the sort of criteria that are appropriate in such cases, such as their explanatory power, their simplicity, the degree to which they rely on numerous unverified assumptions, their consistency with the evidence, their logical properties, and so on. What is required is discussion and debate designed to find the truth, not techniques to estimate which theory arouses the most intense preferences among its advocates. ${ }^{29}$ The same would apply, mutatis mutandis, to decisions concerning somebody's guilt or innocence of some criminal offence, or which person would make the best Prime Minister.

${ }^{29}$ O'Neill (1993, pp. 68-71), Keat (1994, pp. 337/8). 


\section{The Role of CV and CBA}

\subsection{The crucial question of resource constraints}

Debate is all very well and not just as a means of influencing peoples' preferences. But what exactly is to be debated and what happens after the debate? Here, the critics of $\mathrm{CV}$ and CBA are mostly silent, with a few notable exceptions. ${ }^{30}$ Most critics of $\mathrm{CV}$ in environmental valuations either fail to recognise the problem of resource constraints in environmental policy, or do not seem to recognise its full significance. Yet if there were no limitation on resources there would not be much to debate. This is a crucial difference between, on the one hand, debates about issues such as the truth of alternative scientific theories or the morality of abortion, and, on the other hand, the best way to allocate resources between, say, environmental protection and competing uses of resources.

Whatever decision is reached concerning the truth of evolution as against creationism, or the morality of abortion, has no effect on resource allocation and does not reduce the amount of resources that can be devoted to building hospitals, schools, public infrastructure, concert facilities, and so on. By contrast, in the absence of resource limitations, what would there be to debate as regards environmental protection? Everybody would be in favour of it, in the same way that everybody is against sin. The only problem is that in devoting resources to environmental protection less resources are available for other uses.

30 Anderson clearly recognise the problem of resource limitations but does not go far into the precise type of institutional arrangement that would reconcile them with the requirements of appropriate modes of valuation (1993, pp. 210-216), and Brian Barry (1995, pp.143-159) is chiefly concerned with showing that a referendum does not necessarily imply a return to 'want satisfaction' as distinct from 'ideal satisfaction'. 
Michael Jacobs takes up the challenge of finding an alternative to the market that would be necessary to reconcile the theoretical implications of plural values with some practical experience of the way that different 'consultative' bodies sometimes operate (Jacobs, 1995). One important point that he makes is that one should distinguish between two types of decision. The first would be the large-scale decision, involving major developments and affecting a wide range of people. These decisions are presumably the subject of debate, with the limitation on this process indicated above. The second type of decision would be much more local such as how frequently to fell trees in a given area, how much land to preserve there for recreational purposes, and so on. In Britain innumerable such decisions are made every day by various local authorities and other bodies, and usually without any public debate. This type of decision raises another difficulty discussed in the next section.

Jacobs recognises, in fact, that the existing machinery for making either type of decision is far from adequate for reconciling the conflict between resource limitations and the environmental values held by many people. ${ }^{31}$ However, although there is a vast literature on the efficacy of various political institutions for reaching complex decisions of different kinds the special problem of how to incorporate the need for public debate about environmental issues into any representative political institutions is relatively new. It raises difficult practical problems as well as difficulties in political and social choice theory. ${ }^{32}$

\subsection{Repetitive choice and the 'embedding' problem}

31 Jacobs says that 'Public enquiries have almost always been creatures of the state structured to arrive at the outcome the government desires. Their judges or inspectors, the scope of their terms of reference, their accessibility to the public and poorly-funded pressure groups and their procedures have all been heavily criticised' (Jacobs 1995, p.12).

${ }^{32}$ A full discussion of the role of 'expressive returns' in the political theory of electoral preferences that also takes account of the economist's approach to social choice is contained in Brennan and Lomasky 1993, esp. ch.3. See, also, Weale (1992, ch.5). 
It is hardly feasible to hold a debate (followed by some sort of vote) over every single local project involving a road, or a dam, or a forest clearing, or the installation of electricity pylons, and so on. And even if it it were feasible the process is subject to an objection very much like the so-called 'embedding' objection that has been levelled at CV surveys.

For example, suppose that, after due regard to the arguments, the citizens of some community vote to incur the cost of a tunnel in order to prevent a motorway running through their neighbourhood. But the following month they are asked to debate whether they wish to incur heavy costs to preserve some forest. If they had not already committed themselves to the tunnel they might well have been prepared to use up other resources to protect the forest but, having made the commitment to the tunnel, they might be far less willing to do so. And if they did they might then refuse when a vote is taken concerning some expenditures, in the following month, for yet another environmental project. Thus voting about individual projects no more brings out the public's stand on 'ideals' as a whole than do questionnaires about willingness to pay to clean up one part of one lake bring out the public's concern for preserving lakes in general. In short, most

environmentalist critics of $\mathrm{CV}$ have failed to recognise the difference between votes over 'once-for-all' issues, such as legalising abortion, and recurring issues which would be typical of nearly all environmental choices.

\subsection{The unidentified victims of environmental protection}


A further limitation on public debate over every individual environmental decision that needs to be made is that most of the beneficiaries of environmental protection can usually be more or less identified and organized, whereas those who bear the burdens cannot. For example, suppose it would cost £x million to carry out some environmental preservation project - e.g. restore and protect some area of potential scenic beauty - that would give much satisfaction to local residents or to other people not too far away who would enjoy visiting the site in question if suitably restored or protected. Most of these beneficiaries can be identified and, indeed, often organise themselves into pressure groups.

But it is impossible to identify those who bear the cost of the project. In the absence of any special circumstances, the best assumption to make is that the resources are taken away from individual components of total national final expenditures in the same proportion that they bear to the total. This would mean that about 65 percent of the cost would fall on private consumption and the rest on investment and public expenditures on health, education, law and order, housing, and so on.

The victims of the environmental project, therefore, cannot be identified and hence cannot be expected to organise themselves into pressure groups that can participate effectively in the debate and the subsequent vote, let alone to demonstrate, chain themselves to railings, lobby members of Parliament, and so on. Nor should all of these alternative uses of resources be despised by those in favour of the environmental project, or be assumed to be less worthy of respect than the beautiful countryside to be preserved. Some of the other uses of resources may be for purposes that would be regarded as equally desirable in terms of 'ideals' or 'higher modes of valuation' as is the environment. ${ }^{33}$ The great advantage of CBA

\footnotetext{
33 This point has been well put in The Economist, Dec. 3rd 1994, p.106.
} 
is its potential for resolving disputes over resource allocation in a reasonably democratic nature. ${ }^{34}$ By taking account of the costs of carrying out any environmental project all other rival claims on resources will be represented.

\subsection{Elitism and paternalism}

Thus if CBA is rejected and individual environmental decisions are determined by public debate, which is followed up by some voting or referendum, the outcome will not fairly represent all the people affected by the decision. There is also the danger that the people who will be most influential in advocating environmental protection or renovation are likely to be, on the whole, local elites. ${ }^{35}$ The ordinary man in the street is likely to be less able to spend time on such issues and probably less likely to be passionately concerned with them. On the other hand, as Norton rightly points out, 'There may be dangers of paternalistic excesses in the moralistic streak of environmentalism, but these are dangers shared by all moralists and persuaders' (Norton, 1994, p.324).

34 However Anderson rightly draws attention to certain undemocratic aspects of CBA (Anderson 1993, pp.210-212).

35 This point is recognised by some critics of CV and CBA, including Anderson (1993, p.215) and O'Neill (1993, pp.80-81). It is one of the points that Pearce rightly emphasises (1994, pp.1330-1336) 


\section{Conclusions}

The validity of using CV surveys in the assessment of environmental projects depends on various assumptions that may be valid only as regards ordinary marketable goods and services. Two assumptions in particular are at issue here. First, there is the value judgement - already much disputed among economists - to the effect that normative value resides in the expenditure patterns by which people 'reveal' their interests. Secondly, there is the positive assumption that individuals can value the environment in a manner that is commensurate with their valuations of ordinary marketable commodities. This paper has concentrated on the latter assumption, chiefly from the point of view of the plurality of values, and it has been shown to be no more robust than the others.

However, while the criticisms of CV lead to the conclusion that what is required is some role for public debate and discussion concerning environmental policies in order to facilitate the emergence of a view as to which policies are 'right', it is far from clear what kind of institutions can properly fulfill this function. Public debate may be the obvious means for reaching decisions on the rightness of policies concerning, say, abortion or voluntary euthanasia - policies that have few, if any, resource constraints. But it is less obvious that it can operate effectively when the whole problem is that there are resource constraints. In the absence of such constraints everybody would be in favour of environmental protection and there would be nothing to debate.

The failure of most environmentalist critics of $\mathrm{CV}$ to take account of resource constraints has meant that there has been very little progress in elaborating the political mechanisms that are required. But until both sides to the dispute recognise what is valid in their opponents' arguments no progress can be expected. 
The economists need to accept - however much it goes against deeply ingrained habits of thought - that non-use values cannot be captured in any CV in a manner that is strictly commensurate with ordinary market values. The environmentalists need to recognise the full significance of the fact that the resource constraint enters into the environment question in a way that it does not enter into issues such as abortion, assessing the validity of a scientific theory, or the election of a Prime Minister. 


\section{References:}

Aldred, J. 1994, Existence Value, Welfare and Altruism, Environmental Values, vol.3, n.4, Winter 1994

Anderson, E. 1993, Value in Ethics and Economics, Harvard University Press, Cambridge, Mass.

Arrow, K. and Solow, R.M, et al. 1993, Report of the NOAA Panel on Contingent Valuation, National Oceanic and Atmospheric Administration, National Resource Damage Assessment Under the Oil Pollution Act of 1990, Appendix I, Federal Register, vol.58, no. 10, Jan.

Barry, B. 1995, Justice as Impartiality, Clarendon Press, Oxford

Brennan, G. and Lomasky, L. 1993, Democracy \& Decision, Cambridge University Press, Cambridge.

Chang, R. (ed.), 1995, Incommensurability and Value, Harvard University Press, Cambridge, Mass.

Diamond, P.A. and Hausman, J.A. 1994, 'Contingent Valuation: Is Some Number Better than No Number?', Journal of Economic Perspectives, vol. 8, no. 4, pp.45-64.

Elster, J. and Hylland, A. 1986, Foundations of social choice theory, Cambridge University Press, Mass.

Etzioni, A. 1988, The Moral Dimension, The Free Press, New York.

Hargreaves Heap, S. et al. 1992, The Theory of Choice, Blackwell, Oxford.

Griffin, J. 1988, Well-being. Its Meaning, Measurement and Moral Importance, Clarendon Press, Oxford.

Jacobs, M. 1995, Environmental Valuation, Deliberative Democracy and Public DecisionMaking Institutions, draft of July 1995, to be published in Foster, J. (ed.) Valuing Nature, Routledge, London.

Kahneman, D. and Knetsch, J. 1992, 'Valuing Public Goods: The Purchase of Moral Satisfaction', Journal of Environmental Economics and Management, vol.22.

Keat, R. 1994, 'Citizens, Consumers and the Environment: Reflections on The Economy of the Earth', Environmental Values, vol 3, no.4.

Nagel, T. 1979, 'The Fragmentation of Value', in Mortal Questions, Cambridge University Press, Cambridge.

Nagel, T. 1980, 'The Limits of Objectivity', in S. McMurrin (ed.) The Tanner Lectures on Human Values vol. 1, Cambridge University Press, Cambridge. 
Norton, B. 1994, 'Economists' Preferences and the Preferences of the Economists', Environmental Values, vol.3, no.4.

O'Neill, J. 1993, Ecology, Policy and Politics. Human Well-being and the Natural World, Routledge, London.

Parfit, Derek, 1981, 'Prudence, Morality and the Prisoner's Dilemma', Proceedings of the British Academy for 1979, Oxford University Press, Oxford.

Pearce, D.W. 1994, 'Commentary', Environment and Planning A, vol. 26, pp.1329-1338.

Phelps, E.S. (ed.) 1975, Altruism, Morality and Economic Theory, Russell Sage Foundation, New York.

Pigou A.C. 1934, The Economics of Welfare, Macmillan, 4th edn . London.

Raz, J. 1986, The Morality of Freedom, Clarendon Press, Oxford.

Raz, J. 1991, 'Mixing Values', Proceedings of the Aristotelian Society, Supplementary Volume LXV, pp. 83-100.

Sagoff, M. 1994, 'Four Dogmas of Environmental Economics' Environmental Values, vol.3, no.4.

Sen, A.K. 1977, 'Rational Fools: a critique of the behavioural foundations of economic theory' Philosophy and Public Affairs, reprinted in Sen, 1982.

Sen, A.K. 1979, 'Personal Utilities and Public Judgements: or What's Wrong with Welfare Economics?' reprinted in Sen, 1982.

Sen, A.K. 1982, Choice, Welfare and Measurement, Blackwell, Oxford.

Sen, A.K. 1987, On Economics and Ethics, Blackwell, Oxford.

Simon, Herbert A. 1979, 'From substantive to procedural rationality', in Hahn and Hollis (eds).

Smart, J.C.C and Williams, B. 1973, Utilitarianism. For and Against. Cambridge University Press, Cambridge.

Stocker, M. 1990, Plural and Conflicting Values, Oxford University Press, Oxford.

Stocker, M. 1995, 'Abstract and Concrete Value: Plurality, Conflict and Maximization', in Chang, R. (ed.).

Sunstein, C.R. 1995, 'Incommensurability and Kinds of Valuation: Some Applications in Law' ,in Chang, R (ed.),

Taylor, C 1991, 'The Diversity of Goods', in Sen, A. and Williams, B. (eds), Utilitarianism and beyond, Cambridge University Press Cambridge. 
Vadnjal, D. and O'Connor, 1994, 'What is the Value of Rangitoto Island?', Environmental Values, vol.3,no.4.

Weale, Alan (1992) 'Homo Economicus, Homo Sociologicus', in Hargreaves Heap, S. et al., The Theory of Choice, Blackwell, Oxford.

Williams, Bernard 1976, Morality, Cambridge University Press, Cambridge.

Williams, Bernard 1993, Ethics and the Limits of Philosophy, Fontana, (3rd impression), London. 